\title{
Postintubation Dysphagia During COVID-19 Outbreak-Contemporary Review
}

\author{
Zofia Frajkova $^{1,2} \cdot$ Miroslav Tedla $^{1,3}\left(\right.$ Eva Tedlova $^{4} \cdot$ Magda Suchankova $^{5} \cdot$ Ahmed Geneid $^{6}$
}

Received: 22 April 2020 / Accepted: 20 May 2020 / Published online: 28 May 2020

(c) Springer Science+Business Media, LLC, part of Springer Nature 2020

\begin{abstract}
The COVID-19 is a global pandemic. Its rapid dissemination and serious course require a novel approach to healthcare practices. Severe disease progression is often associated with the development of the Acute Respiratory Distress Syndrome and may require some form of respiratory support, including endotracheal intubation, mechanical ventilation, and enteral nutrition through a nasogastric tube. These conditions increase the risk of dysphagia, aspiration, and aspiration pneumonia. The data on the incidence and risks of dysphagia associated with COVID-19 are not yet available. However, it is assumed that these patients are at high risk, because of respiratory symptoms and reduced lung function. These findings may exacerbate swallowing deficits. The aim of this review is to summarize available information on possible mechanisms of postintubation dysphagia in COVID-19 patients. Recommendations regarding the diagnosis and management of postintubation dysphagia in COVID-19 patients are described in this contemporary review.
\end{abstract}

Keywords Swallowing $\cdot$ Postintubation dysphagia $\cdot$ COVID-19 $\cdot$ Deglutition $\cdot$ Deglutition disorders

\section{Introduction}

The COVID-19 disease spread from Wuhan, China, in December 2019 [1], was named SARS-CoV-2 [2] by WHO and declared a pandemic on March 11,2020. The virus is transmitted primarily by droplet infection [3] during human

Zofia Frajkova and Miroslav Tedla have equally contributed to this work and are considered to be joint first authors.

Miroslav Tedla

miro.tedla@gmail.com

1 Department of ENT and HNS, Faculty of Medicine, University Hospital Bratislava, Comenius University, Antolska 11, 81107 Bratislava, Slovakia

2 Department of Communication Disorders, Faculty of Education, Comenius University, Bratislava, Slovakia

3 Institute of Cancer and Genomic Sciences, University of Birmingham, Birmingham, UK

4 Department of Pneumology, Faculty of Medicine, Comenius University, Bratislava, Slovakia

5 Institute of Immunology, Faculty of Medicine, Comenius University, Bratislava, Slovakia

6 Department of Otorhinolaryngology and Phoniatrics-Head and Neck Surgery, University of Helsinki and Helsinki University Hospital, Helsinki, Finland contact [1, 4]. Main symptoms in hospitalized patients are fever, cough, myalgia, and fatigue [5]. Dyspnoea occurred in $55 \%$ of patients [5]. The disease is characterized by progressive respiratory failure and even death [6] in a minority of infected patients. Severe disease progression is associated with the development of the Acute Respiratory Distress Syndrome (ARDS) and may require mechanical ventilation [7].

The need for intensive care in ARDS patients without COVID-19 is from 3 to $32 \%$ in previously published papers [5, 8-10]. Intubation and mechanical ventilation are associated with the risk of dysphagia. One-third of intubated patients after ARDS had dysphagia on discharge from the hospital.[11]. Therefore, it is necessary to use uniform, reliable protocols to identify dysphagia during hospitalization [11]. However, the care of patients with postintubation dysphagia and COVID-19 has its own specifics to be followed when providing healthcare.

Swallowing is a complex process requiring interaction and proper coordination of sensory and motor mechanisms [12]. A coordinated swallowing act requires the involvement of more than 30 muscles and six cranial nerves [13]. The goal of swallowing is the safe passage of saliva, liquids, and solids from the mouth to the stomach [14]. Swallowing disorders (dysphagia) are known to be associated with an increased risk of aspiration and aspiration pneumonia, 
delayed oral feeding, malnutrition and decreased quality of life.[15]. Intensive care of critically ill patients may require some form of respiratory support including endotracheal intubation and/or mechanical ventilation. For adequate nutrition, it is necessary to start an enteral nutrition through a nasogastric tube. These conditions increase the risk of dysphagia, aspiration, and aspiration pneumonia [16]. In the context of intensive care, dysphagia leads to prolonged hospitalization, increases morbidity, and mortality [17]. Moderate and severe dysphagia after extubation is associated with the need for reintubation, pneumonia and a high risk of death [18]. Limited options of diagnostic and therapeutic procedures for management of postintubation dysphagia are available [19]. The aim of this review is to summarize available information and recommendations on the diagnosis and management of postintubation dysphagia in COVID-19 patients.

\section{Causes of Postintubation Dysphagia}

Postintubation dysphagia in critically ill patients is related to the duration of mechanical ventilation [18, 20-22], negatively affects the return to oral intake, and is associated with prolonged hospitalization [23]. In patients requiring endotracheal intubation, the occurrence of dysphagia is due to multifactorial changes [20,24], mainly mechanical and cognitive [25]. The endotracheal tube passes through the oral cavity, oropharynx, larynx, and trachea. There is a risk of laryngeal and tracheal injury, postintubation voice disorder, and dysphagia [26]. Several authors point out that postintubation dysphagia may be underdiagnosed [24, 27]. The presence of dysphagia increases the risk of aspiration pneumonia. However, dysphagia is not the only predictor of aspiration pneumonia in patients after extubation. The laryngeal sphincter is a key protective mechanism of the lower respiratory tract [28]. The oral flora of intubated patients contains pathogenic bacteria [29]. Shifting oral secretions through the larynx into the lower respiratory tract can cause infections and inflammatory pulmonary complications [30]. The second way to develop aspiration pneumonia is by aspiration of gastric content [29]. Aspiration may lead to acute desaturation, pneumonia or pneumonitis, and the need for reintubation, which increases the length of stay in the hospital [31]. Aspiration pneumonia is one of the 10 most common rehospitalization diagnoses after severe sepsis [32]. According to Kim et al. [33] the duration of endotracheal intubation is independently associated with aspiration and the duration of intubation positively correlates with the degree of dysphagia, which may help in identifying patients requiring swallow examination [33].

Predictive factors increasing the risk of dysphagia and aspiration after extubation include age, changes in voice quality and the degree of voice disorder [34]. Another factor that affects the incidence of dysphagia in critically ill patients is whether the patient has already had dysphagia prior to the intubation or developed it as a result of the current disease [31]. One systematic review concluded that surgical and medical risk factors for dysphagia after extubation are congestive heart failure, functional status, increased hospital length of stay, hypercholesterolemia, increased ICU length of stay, multiple intubations, increased operative time, perioperative transesophageal echocardiography, and sepsis [35]. In another study in patients after cardiac surgery, the duration of intubation has been confirmed to be a strong predictor of dysphagia [23]. One study reported that the predictor of aspiration risk is intubation lasting more than 7 days [34].

\section{Incidence}

Information on the incidence of dysphagia in extubated patients varies. This is mainly due to methodological discrepancies, different methods of diagnosis and inconsistent evaluation intervals after extubation. In patients intubated for more than $48 \mathrm{~h}$, the prevalence of dysphagia increases by $56 \%$, of which $25 \%$ patients aspirate silently [20]. Another study concludes that dysphagia is associated with intubation lasting more than 4 days [36]. According to other studies, dysphagia occurs in $3 \%$ to $62 \%$ of patients recovering after critical illness [31]. According to preliminary data, the average length of hospitalization at ICU is 7 to 8 days $[8,37,38]$. The data on the incidence and risks of dysphagia associated with COVID-19 are not yet available. However, we assume these patients are at high risk. The possible mechanisms of dysphagia in extubated patients with COVID-19 are described in more detail below.

\section{Mechanisms of Development of Postintubation Dysphagia}

Dysphagia developed as a consequence intensive care and orotracheal intubation have six potential mechanisms of development [31] summarized in Table 1.

\section{Oropharyngeal and Laryngeal Trauma}

The mechanical causes of postintubation dysphagia are related to intubation itself, duration of intubation and endotracheal tube characteristics [20]. Oropharyngeal trauma is associated with oral and pharyngeal phase of swallowing. Injury to the lips may result in drooling of saliva and bolus [39]. Dental damage occurs mainly in patients with known dental diseases, such as dental caries and periodontitis [40]. 
Table 1 Potential mechanisms of dysphagia in ICU adapted according to Macht et al. (2013)

Mechanisms contributing to the development of dysphagia

Oropharyngeal and laryngeal trauma

Neuromuscular weakness

Reduced laryngeal sensitivity

Altered sensorium

Gastroesophageal reflux

Impaired synchronization of breathing and swallowing

Immediately after extubation, the oral cavity is frequently dry, with dried secretions around the lips, tongue, and hard palate. In elderly patients, chewing may be impaired due to lack of dentition and possible cognitive deficits [16]. In the pharyngeal phase of swallowing, impaired elevation of the hyolaryngeal complex and the laryngeal sphincter may increase the risk of aspiration [28]. Impairment can be caused by edema of oropharyngeal and laryngeal structures [16]. Laryngeal edema is one of the most frequent and serious complications of tracheal intubation [42]. Endotracheal intubation may cause mucosal abrasion [43], inflammations, hematomas, and ulcerations in the area of vocal cords, arytenoids, epiglottis, and the base of tongue [31]. Intubation may also result in dislocation [33] and subluxation of the arytenoid cartilage [19], which compromises the closure of the laryngeal vestibule [44]. A specific situation is injury of the recurrent laryngeal nerve, the endotracheal tube cuff can compress the branch of the recurrent laryngeal nerve [31]. Vocal cord paresis may occur, depending on the type of tube [45], cuff size [46], and cuff pressure [47], quality, and duration of intubation [48]. Laryngeal trauma arises the risk of insufficient laryngeal sphincter during swallowing, which leads to the likelihood of aspiration. Any type of laryngeal injury can be a risk factor for dysphagia [49]. In an extubated patient, oropharyngeal, and laryngeal trauma contributes to the development of respiratory distress, voice disorders, and swallowing disorders [48].

\section{Neuromuscular Weakness}

As mentioned above, a normal swallowing act requires the involvement of more than 30 muscles and six cranial nerves [13]. Intubation may cause atrophy of the structures involved in swallowing act [50]. Orotracheal intubation tube retains glottis open for extended periods of time, inhibiting the natural movement of the laryngeal and pharyngeal muscles [30]. Movements of the intrinsic muscles of the larynx, which are necessary, e.g., in reflexive vocal cord closure, are also negatively affected by the presence of the orotracheal intubation tube [30].

Neuromuscular weakness may be a consequence of:
- prolonged non-use of structures during long-term intubation [50],

- prolonged analgosedation [17],

- long-term use of neuromuscular blocking agents [17].

Neuromuscular weakness during swallowing act leads to dyscoordination of muscles and nerves [51], is associated with the incidence of dysphagia and an increased risk of aspiration [52]. In association with oropharyngeal or laryngeal trauma, it may cause a decrease in local sensitivity, leading to swallowing dysfunction. This is proved by the study of Brodsky et al. [51], who identified significant changes in the pharyngeal phase of swallowing, specifically slowing of the muscles involved in swallowing act, indicating neuromuscular weakness in ARDS patients.

\section{Reduced Sensitivity}

Reduced sensitivity of upper respiratory tract is another potential factor of developing dysphagia in patients after extubation [31]. Clinically, this is manifested when the bolus passes from the oral to the pharyngeal phase [53]. Limited sensitivity of bolus and secretions in the hypopharynx interferes with the protective reflexes of swallowing [54]. Sensitive deprivation causes rapid changes in chemoreceptors and mechanoreceptors of upper respiratory tract and may last about seven days after extubation [34, 41]. If afferent input is impaired, aboral movement of the bolus through the reflection zone triggering swallowing will delay swallowing [17], resulting in predeglutive aspiration [55].

\section{Altered Sensorium}

The fourth mechanism of swallowing impairment is altered sensorium [31], related to the development of delirium [31]. Qualitative or quantitative disorder of consciousness increases the risk of aspiration and may delay therapy for dysphagia [17]. Sensory changes can also be attributed to the residual effect of narcotic and anxiolytic medication [50]. The ability to answer orientation questions and follow simple verbal instructions provides information on the likelihood of liquid aspiration and the overall diet of the patient. Patients with impaired ability to answer questions and follow simple instructions were $31 \%$ more likely to aspirate liquids than patients with the maintained perception of questions and instructions [56].

\section{Gastroesophageal Reflux (GERD)}

Gastroesophageal reflux is the fifth possibility of developing dysphagia in critically ill patients. The risk of developing GERD is increased by the presence of nasogastric tube, lying position, high doses of sedation, and the use of 
paralytic agents in therapy [31]. GERD adversely affects laryngeal sphincter function, increasing the risk of aspiration [57]. Chronic GERD may contribute to the development of postintubation dysphagia [28]. The nasogastric tube often remains in place after extubation as a non-oral form of nutrition and hydration of the patient. Since inserted nasogastric tube means a constant opening of the upper and lower oesophageal sphincter, there is a risk of aspiration of gastric content [58].

\section{Impaired Respiratory-Swallowing Coordination}

The sixth mechanism of postintubation dysphagia is associated with impairment of synchronization between respiration and swallowing [59]. Swallowing and respiration are highly coordinated actions [60]. During swallowing, breathing is briefly interrupted not only because of laryngeal closure, elevation of the soft palate and epiglottic inversion, respiration is also suppressed at the brainstem level [61]. When drinking liquid, swallowing begins during exhalation. The respiratory pause lasts 0,5 to $1,5 \mathrm{~s}$ during swallowing, respiration usually starts during exhalation [62]. This restoration is considered to be one of the mechanisms preventing the aspiration of bolus after swallowing [28]. Eating solid food also changes the respiratory rhythm. The rhythm is impaired at the start of chewing. The duration of the respiratory cycle during chewing is reduced. The "exhale-swallow-exhale" relationship persists during eating. However, respiratory pauses are longer, usually starting before swallowing [63]. Dysphagia may be related to tachypnoea [28]. Prevention of aspiration depends on the accuracy of coordination of laryngeal closure, apnoea pause, and opening of upper oesophageal sphincter [31].

The underlying pathomechanism of postintubation dysphagia is thought to determine its duration [29]. Usually, oropharyngeal, and laryngeal trauma normalizes within few days. However, neuromuscular weakness with muscle atrophy may persist over the long term and requires further intervention [28]. Elderly patients may have more comorbidities and neuromuscular weakness due to the aging process. Therefore, they recover longer from postintubation dysphagia [64].

\section{Specifics of Postintubation Dysphagia Management in COVID-19 Patients}

In addition to the described mechanisms of dysphagia in extubated patients, patients with COVID-19 have specific characteristics. As a result of the disease they have reduced lung function $[65,66]$ in terms of short and weakened breathing limiting physical activity in the initial phase of rehabilitation [6]. Some patients may also develop a lung fibrosis $[6,67,68]$.
The disease is more severe in elderly population [69]. Other studies specify that a more severe course is in elderly men with comorbidities $[4,70]$. In the diagnostics of patients with postintubation dysphagia, it is important to evaluate the mechanisms of impairment associated with COVID-19. Therefore, reduced lung function, social deprivation, age, and history of comorbidities of the patient should be taken into consideration. These findings may exacerbate swallowing deficits. The incidence, diagnosis, and management of dysphagia in COVID-19 patients have not been reported. However, we assume that the consequences of intubation may be manifested by impairment of the swallowing act and attention should be paid to the management of dysphagia in these patients.

Some diagnostic and therapeutic measures of dysphagia are considered aerosol-generating procedures. It is recommended to modify particular procedures limiting the usage of instrumental swallowing examinations [71, 72]. In Flexible Endoscopic Evaluation of Swallowing (FEES) procedure, the risk of transmitting COVID-19 is extremely high [73]. During the examination the endoscope passes through the nasal cavity and nasopharynx into the oropharynx [71], from mucosal surfaces of these structures virus is detectable [74]. The contact between the patient and the investigator must be within a short physical distance, which is a potential route for airborne infection [73]. In the implementation of aerosolgenerating processes, healthcare workers are exposed to pathogens causing acute respiratory infections [75]. These workers are at high risk of transmitting infection. Only endoscopy in urgent situations is recommended [76]. The same recommendations apply to videofluoroscopy, it is recommended to postpone these examinations [77]. Videofluoroscopy (VFS) should only be performed if there is a high risk of aspiration and malnutrition/dehydration due to dysphagia and inability to feed non-orally [78]. If VFS is performed, the patient should feed themselves to minimize risk of aerosol spread [78], while ensuring the protection of the patient, healthcare professionals and equipment according to national and specific hospital regulations. All COVID-19 patient care processes, including assessment and therapy of dysphagia, must be accompanied by strict protective regulations. Consideration should also be given to postponing swallowing examinations unless an examination is necessary, or to instruct and coach a physician or other healthcare professional and to provide guidance during the swallowing examination or intervention [72].

\section{Evaluation of Swallowing in Patients with COVID-19 After Orotracheal Intubation Tube Removal}

Swallowing screening is a quick way to identify the likelihood of dysphagia, the need for further swallow examination [18], the safety of oral food intake, and the need for an 
alternative form of nourishment [79]. The aim of the screening test is to identify as many patients at risk of dysphagia as possible before the clinical manifestation of dysphagia symptoms [80] and minimize the risk of aspiration [34]. The screening of dysphagia involves testing of various consistencies of diet and fluid [29].

Early detection of postintubation dysphagia is needed to reduce the incidence of complications [50]. Systematic screening is crucial in identifying and monitoring patients at risk [81]. In extubated patients it is recommended that rapid, sensitive screening be carried out by a trained nurse in the ward in order to avoid exposing other health professional to risk of infection [29]. The managing physician should consider diagnostic strategies and pathways of dysphagia management including telehealth and digital measures. If the patient has a known history of neurological disease, head and neck surgery, or prolonged mechanical ventilation, screening may be avoided and a detailed examination of swallowing by the speech and language therapist should be considered.

The timing of the swallow assessment after patient extubation varies in studies and there is no consensus on screening. Screening takes place 1 to 5 days after extubation [35]. Other studies suggest that swallowing assessment does not need to be delayed [36, 82], with more than $82 \%$ of patients completing swallowing screening in the first hour after extubation [36]. When screening $24 \mathrm{~h}$ after extubation, penetration and aspiration were significantly reduced, and respiratory protection was improved in $79 \%$ of patients compared to screening immediately after extubation. This suggested that swallowing function significantly improved during the first day after extubation. According to this study, patients may start with an oral intake of consistency that is safe to swallow, but delayed screening ( $24 \mathrm{~h}$ after extubation) allows for a faster return to a less restricted diet [83].

A number of screening tools have been developed for different groups of patients with neurological, structural, and inflammatory disease [84-86]. Some screenings have also been used in patients after extubation, but without demonstrating their sensitivity and specificity in this group of patients [27, 87]. Although postintubation dysphagia has been identified for decades, standard protocols for screening and diagnosis of postintubation dysphagia are still unclear $[88,89]$. Swallowing screening has been developed for patients intubated for more than $48 \mathrm{~h}$ [90]. This screening is performed by a nurse. It contains specific items related to possible mechanisms of dysphagia after prolonged intubation. Screening sensitivity is $81 \%$ and specificity is $69 \%$, positive predictive value $77 \%$ and negative predictive value $74 \%$ [90]. The advantage of this screening in the context of COVID-19 may be that some of the items the nurse administers can be traced from patient's medical records, reducing the contact time with the COVID-19 positive patient and hence the risk of virus transmission. The authors of the screening test conclude that the assessment of the risk of dysphagia administered by a nurse is particularly appropriate when the speech therapist is not directly available [90], which may also be applicable at the time of COVID-19 pandemics. In the screening of swallowing after extubation, the risk of dysphagia was mainly associated with drooling, multiple swallowing, coughing, and voice change during swallowing [91]. These signs indicating swallowing difficulties can be evaluated by the nurse or healthcare professional even from a safe distance from the patient to reduce the risk of transmission of the virus.

Screening should indicate the need for further clinical or instrumental examination of swallowing [50]. As mentioned above, carrying out instrumental swallowing examinations is not recommended due to the high risk of airborne virus transmission. If a speech therapist is available, a clinical swallow examination may be performed.

Clinical swallow examination is an organized, goal-oriented examination of swallowing act [92]. It aims to confirm the predicted state of swallowing and to determine the nature and extent of the swallowing impairment [93]. The primary objective of a clinical swallow examination is to determine the patient's ability to swallow as the opposite of inability [94]. Due to the complexity of this method, the investigator can formulate a patient management plan, measure progress, and guide the form and type of any other intervention options. The specificity of an extubated patient with COVID-19 should be a thorough study of the patient's medical records and information from the nursing staff or the patient's family/carer. If possible, telephone or other remote contact should be preferred. When interacting with a patient, it is recommended that the examiner stands at the side of the bed and performs the examination at the end of the day while minimizing the risk of transmission of the virus to other patients.[95]. Reflex cough testing should be omitted in every patient with COVID-19 [78]. In an extubated patient, the examination includes evaluation of saliva stasis, cough during swallowing, gag reflex, and tongue movements [58]. In COVID-19 patients, it is recommended to stand about $2 \mathrm{~m}$ away from the patient while evaluating oromotor function [95]. Closer contact is permitted when assessing oral mucosa, palate, and dentition. It is recommended to use light to improve the view [95]. During entire examination, appropriate personal protective equipment (PPE) should be worn [72]. The presence of cough after swallowing liquid or thickened liquid is the most reliable clinical sign of dysphagia $[58,91]$. Cough after swallowing liquid and thickened liquid is a contraindication to oral intake. If the cough is only after swallowing liquid, it is possible to modify the consistencies of the diet [58]. For consistency testing, it is recommended to skip laryngeal palpation and stand at a distance of $2 \mathrm{~m}$ from the patient. If closer contact is needed, the investigator 
should stand side of the bed facing away from the patient [95]. However, bedside examination may be partially unspecific in extubated patients, as patients recovering from a critical illness may have a cough and gargling voice for reasons other than the aspiration [29]. In patients with other comorbidities, a history of neurological diseases, in geriatric patients, patients with known dysphagia, other mechanisms of swallowing impairment are also possible.[58]. Patients with prolonged intubation should have assessed swallowing before the first oral intake [58]. Once non-oral feeding is necessary, NG tube should be preferred to PEG due to the simplicity of insertion and minimizing risks to both patient and the healthcare providers. This is keeping in line with the recommendations to reduce risks the aerosol-generating procedures. Understanding the pathophysiology of postintubation dysphagia is crucial in choosing the appropriate procedure for further patient management [28].

\section{Key Recommendations for Postintubation Dysphagia in COVID-19 Patients}

- Dysphagia after long-term orotracheal intubation is a major concern. In general, prevalence of dysphagia is being increased in $56 \%$ of patients after $48 \mathrm{~h}$ of orotracheal intubation.

- No data regarding postextubation dysphagia in COVID19 patients is available at the moment. Both short- and long-term impairment can be expected as the virus may cause a decrease of lung function and pulmonary fibrosis may also develop.

- In COVID-19 positive patients risk of aspiration/dysphagia should be assessed while coping with epidemic measures. Close contact with the COVID-19 positive patient should be minimized. Remote diagnostics/ giving recommendations might be considered.

- Dysphagia screening tool should be administered by the nursing staff to minimize contact to SALT/other non-vital members of the ICU team.

- Information should be obtained from patients notes or using telemedicine as much as possible prior to the personal contact.

- In COVID-19 era we recommend keeping swallowing screening tool which has been used after extubation as a standard according to the local ICU policy. If there had not been one in use previously, we recommend using validated screening test of Johnson et al. [90] as described above.

- Once patient fails swallowing screening our practice and advice is to use NG tube rather than PEG tube. This is highly recommended due to the simplicity of insertion and minimizing risks to both patient and the healthcare providers.
- Proper PPE should be worn at all times. Two-meter distance should be maintained during assessment whenever possible. Laryngeal palpation and reflex cough testing should be avoided.

- Instrumental dysphagia diagnostic are aerosol generation procedures and as such the use of FEES and VFS in COVID-19 positive patients should be strictly limited.

- Videofluoroscopy should be performed only in patients with high risk of aspiration/malnutrition where non-oral feeding is possible. Food should be self-administered during examination.

Funding None.

\section{Compliance with Ethical Standards}

Conflict of interest The authors declare that they have no conflict of interest.

\section{References}

1. Zhou P, Yang X-L, Wang X-G, Hu B, Zhang L, Zhang W, et al. A pneumonia outbreak associated with a new coronavirus of probable bat origin. Nature. 2020;579:270-3.

2. Naming the coronavirus disease (COVID-19) and the virus that causes it. [cited 2020 Apr 21]. https://www.who.int/emergencies/ diseases/novel-coronavirus-2019/technical-guidance/naming-thecoronavirus-disease-(covid-2019)-and-the-virus-that-causes-it. Accessed 21 Apr 2020

3. Omer SB, Malani P, Del Rio C. The COVID-19 pandemic in the US: a clinical update. JAMA. 2020;323:1767-8.

4. Cowling BJ, Leung GM. Epidemiological research priorities for public health control of the ongoing global novel coronavirus (2019-nCoV) outbreak. Euro Surveill. 2020;25:2000110.

5. Huang C, Wang Y, Li X, Ren L, Zhao J, Hu Y, et al. Clinical features of patients infected with 2019 novel coronavirus in Wuhan. China Lancet. 2020;395:497-506.

6. Law S, Leung AW, Xu C. Severe acute respiratory syndrome (SARS) and coronavirus disease-2019 (COVID-19): from causes to preventions in Hong Kong. Int J Infect Dis. 2020;94:156.

7. Zareifopoulos N, Lagadinou M, Karela A, Karantzogiannis G, Velissaris D. Intubation and mechanical ventilation of patients with COVID-19: what should we tell them? Monaldi Arch Chest Dis. 2020. https://doi.org/10.4081/monaldi.2020.1296.

8. Grasselli G, Zangrillo A, Zanella A, Antonelli M, Cabrini L, Castelli A, et al. Baseline characteristics and outcomes of 1591 patients infected with SARS-CoV-2 admitted to ICUs of the Lombardy Region. Italy JAMA. 2020;323:1574.

9. Guan W-J, Ni Z-Y, Hu Y, Liang W-H, Ou C-Q, He J-X, et al. Clinical characteristics of coronavirus disease 2019 in China. $\mathrm{N}$ Engl J Med. 2020;382:1708.

10. Meng L, Qiu H, Wan L, Ai Y, Xue Z, Guo Q, et al. Intubation and ventilation amid the COVID-19 outbreak: Wuhan's experience. Anesthesiology. 2020;132:1317.

11. Brodsky MB, Huang M, Shanholtz C, Mendez-Tellez PA, Palmer JB, Colantuoni E, et al. Recovery from dysphagia symptoms after 
oral endotracheal intubation in acute respiratory distress syndrome survivors: a 5-year longitudinal study. Ann Am Thorac Soc. 2017;14:376-83.

12. Panara K, Padalia D. Physiology, swallowing. Treasure Island, FL: StatPearls Publishing; 2020.

13. Costa MMB. Neural control of swallowing. Arq Gastroenterol. 2018;55:61-75.

14. Logemann JA, Larsen K. Oropharyngeal dysphagia: pathophysiology and diagnosis for the anniversary issue of diseases of the esophagus. Dis Esophag. 2012;25:299-304.

15. Garcia JM, Chambers EI. Managing dysphagia through diet modifications. AJN Am J Nurs. 2010;110:26-33.

16. Murry T, Carrau R. The abnormal swallow: conditions and diseases. Clinical management of swallowing disorders, vol. 2. San Diego: Plural Publishing; 2006. p. 17-32.

17. Zuercher P, Moret CS, Dziewas R, Schefold JC. Dysphagia in the intensive care unit: epidemiology, mechanisms, and clinical management. Crit Care. 2019;23:103.

18. Macht M, Wimbish T, Clark BJ, Benson AB, Burnham EL, Williams A, et al. Postextubation dysphagia is persistent and associated with poor outcomes in survivors of critical illness. Crit Care. 2011;15:R231.

19. Christensen M, Trapl M. Development of a modified swallowing screening tool to manage post-extubation dysphagia. Nurs Crit Care. 2018;23:102-7.

20. Ajemian MS, Nirmul GB, Anderson MT, Zirlen DM, Kwasnik EM. Routine fiberoptic endoscopic evaluation of swallowing following prolonged intubation: implications for management. Arch Surg. 2001;136:434-7.

21. de Larminat V, Montravers P, Dureuil B, Desmonts J-M. Alteration in swallowing reflex after extubation in intensive care unit patients. Critic Care Med. 1995;23:486-90.

22. Ma D, Spierer-Rundback L. Swallowing disorders in patients with prolonged orotracheal intubation or tracheostomy tubes. Crit Care Med. 1990;18:1328-30.

23. Barker J, Martino R, Reichardt B, Hickey EJ, Ralph-Edwards A. Incidence and impact of dysphagia in patients receiving prolonged endotracheal intubation after cardiac surgery. Can J Surg. 2009;52:119-24.

24. Smithard DG. Neuromuscular disease and extubation dysphagia. Crit Care. 2013;17:194.

25. Kwok AM, Davis JW, Cagle KM, Sue LP, Kaups KL. Post-extubation dysphagia in trauma patients: it's hard to swallow. Am J Surg. 2013;206:924-8.

26. Brodsky MB, Pandian V, Needham DM. Post-extubation dysphagia: a problem needing multidisciplinary efforts. Intensive Care Med. 2020;46:93-6.

27. Schefold JC, Berger D, Zürcher P, Lensch M, Perren A, Jakob $\mathrm{SM}$, et al. Dysphagia in mechanically ventilated ICU patients (DYnAMICS): a prospective observational trial. Crit Care Med. 2017:45:2061-9.

28. Goldsmith T. Evaluation and treatment of swallowing disorders following endotracheal intubation and tracheostomy. Int Anesthesiol Clin. 2000;38:219-42.

29. Macht M, White SD, Moss M. Swallowing dysfunction after critical illness. Chest. 2014;146:1681.

30. Fernández-Carmona A, Peñas-Maldonado L, Yuste-Osorio E, Díaz-Redondo A. Exploration and approach to artificial airway dysphagia. Med Intensiva. 2012;36:423-33.

31. Macht M, Wimbish T, Bodine C, Moss M. ICU-acquired swallowing disorders. Critic Care Med. 2013;41:2396-405.

32. Prescott HC, Langa KM, Iwashyna TJ. Readmission diagnoses after severe sepsis and other acute medical conditions. JAMA. 2015;313:1055-7.

33. Kim MJ, Park YH, Park YS, Song YH. Associations between prolonged intubation and developing post-extubation dysphagia and aspiration pneumonia in non-neurologic critically Ill patients. Ann Rehabil Med. 2015;39:763-71.

34. Oliveira ACM, Friche AAL, Salomão MS, Bougo GC, Vicente LCC. Predictive factors for oropharyngeal dysphagia after prolonged orotracheal intubation. Braz J Otorhinolaryngol. 2018;84:722-8.

35. Skoretz SA, Flowers HL, Martino R. The incidence of dysphagia following endotracheal intubation: a systematic review. Chest. 2010;137:665-73.

36. Leder SB, Warner HL, Suiter DM, Young NO, Bhattacharya B, Siner JM, et al. Evaluation of swallow function post-extubation: is it necessary to wait 24 hours? Ann Otol Rhinol Laryngol. 2019;128:619-24.

37. Evidence summary for average length of stay in the intensive care unit for COVID-19 I HIQA. https://www.hiqa.ie/reports-and-publi cations/health-technology-assessment/evidence-summary-avera ge-length-stay. Accessed 20 Apr 2020

38. Zhou F, Yu T, Du R, Fan G, Liu Y, Liu Z, et al. Clinical course and risk factors for mortality of adult inpatients with COVID19 in Wuhan, China: a retrospective cohort study. Lancet. 2020;395:1054-62.

39. Komasawa N, Komatsu M, Yamasaki H, Minami T. Lip, tooth, and pharyngeal injuries during tracheal intubation at a teaching hospital. Br J Anaesth Oxford Academic. 2017;119:171-171.

40. Vogel J, Stübinger S, Kaufmann M, Krastl G, Filippi A. Dental injuries resulting from tracheal intubation-a retrospective study. Dent Traumatol. 2009;25:73-7.

41. Jones HN, Rosenbek JC. Dysphagia in rare conditions: an encyclopedia. San Diego: Plural Publishing; 2009.

42. François B, Bellissant E, Gissot V, Desachy A, Normand S, Boulain $\mathrm{T}$, et al. 12-h pretreatment with methylprednisolone versus placebo for prevention of postextubation laryngeal oedema: a randomised double-blind trial. The Lancet. 2007;369:1083-9.

43. Macht M, Wimbish T, Clark BJ, Benson AB, Burnham EL, Williams A, et al. Diagnosis and treatment of post-extubation dysphagia: Results from a national survey. J Crit Care. 2012;27:578-86.

44. Lombardi RA, Arthur ME. Arytenoid subluxation. Treasure Island, FL: StatPearls Publishing; 2020.

45. Tanaka A, Isono S, Ishikawa T, Sato J, Nishino T. Laryngeal resistance before and after minor surgery: endotracheal tube versus Laryngeal Mask Airway. Anesthesiology. 2003;99:252-8.

46. Arts MP, Rettig TCD, de Vries J, Wolfs JFC, In't Veld BA. Maintaining endotracheal tube cuff pressure at $20 \mathrm{~mm} \mathrm{Hg}$ to prevent dysphagia after anterior cervical spine surgery; protocol of a double-blind randomised controlled trial. BMC Musculoskelet Disord. 2013;14:280.

47. Combes X, Schauvliege F, Peyrouset O, Motamed C, Kirov K, Dhonneur $\mathrm{G}$, et al. Intracuff pressure and tracheal morbidity: influence of filling with saline during nitrous oxide anesthesia. Anesthesiology. 2001;95:1120-4.

48. Matta RI, Halan BK, Sandhu K. Postintubation recurrent laryngeal nerve palsy: A review. Journal of Laryngology and Voice. 2017;7:25.

49. Brodsky MB, Gellar JE, Dinglas VD, Colantuoni E, MendezTellez PA, Shanholtz C, et al. Duration of oral endotracheal intubation is associated with dysphagia symptoms in acute lung injury patients. J Crit Care. 2014;29:574-9.

50. Rassameehiran S, Klomjit S, Mankongpaisarnrung C, Rakvit A. Postextubation dysphagia. Baylor University Medical Center Proceedings. Taylor \& Francis; 2017. https://www.tandfonline.com/ doi/abs/10.1080/08998280.2015.11929174. Accessed 4 Apr 2020

51. Brodsky MB, De I, Chilukuri K, Huang M, Palmer JB, Needham DM. Coordination of pharyngeal and laryngeal swallowing events during single liquid swallows after oral endotracheal intubation for patients with acute respiratory distress syndrome. Dysphagia. 2018;33:768-77. 
52. Mirzakhani H, Williams J-N, Mello J, Joseph S, Meyer MJ, Waak $\mathrm{K}$, et al. Muscle weakness predicts pharyngeal dysfunction and symptomatic aspiration in long-term ventilated patients. Anesthesiol Am Soc Anesthesiol. 2013;119:389-97.

53. Bradley RM. Sensory receptors of the larynx. Am J Med. 2000;108(Suppl 4a):47S-50S.

54. Linden P, Siebens AA. Dysphagia: predicting laryngeal penetration. Arch Phys Med Rehabil. 1983;64:281-4.

55. Aviv JE. Clinical assessment of pharyngolaryngeal sensitivity. Am J Med. 2000;108:68-72.

56. Leder SB, Suiter DM, Lisitano WH. Answering orientation questions and following single-step verbal commands: effect on aspiration status. Dysphagia. 2009;24:290-5.

57. Mendell DA, Logemann JA. A retrospective analysis of the pharyngeal swallow in patients with a clinical diagnosis of GERD compared with normal controls: a pilot study. Dysphagia. 2002;17:220-6.

58. Noordally SO, Sohawon S, De Gieter M, Bellout H, Verougstraete G. A study to determine the correlation between clinical, fiberoptic endoscopic evaluation of swallowing and videofluoroscopic evaluations of swallowing after prolonged intubation. Nutr Clin Pract. 2011;26:457-62.

59. Dziewas R, Warnecke T. ICU-related dysphagia. In: Ekberg O, editor. Dysphagia: diagnosis and treatment. Cham: Springer International Publishing; 2019. p. 157-164.

60. Gross RD, Atwood CW, Ross SB, Olszewski JW, Eichhorn KA. The Coordination of breathing and swallowing in chronic obstructive pulmonary disease. Am J Respir Crit Care Med. 2009;179:559-65.

61. Ertekin C. Voluntary versus spontaneous swallowing in man. Dysphagia. 2011;26:183-92.

62. Martin-Harris B, Brodsky MB, Michel Y, Ford CL, Walters B, Heffner J. Breathing and swallowing dynamics across the adult lifespan. Arch Otolaryngol Head Neck Surg. 2005;131:762-70.

63. Matsuo K, Palmer JB. Anatomy and physiology of feeding and swallowing: normal and abnormal. Phys Med Rehab Clin N Am. 2008;19:691-707.

64. Tsai M-H, Ku S-C, Wang T-G, Hsiao T-Y, Lee J-J, Chan D-C, et al. Swallowing dysfunction following endotracheal intubation: age matters. Medicine (Baltimore). 2016;95:e3871.

65. Iwasawa T, Sato M, Yamaya T, Sato Y, Uchida Y, Kitamura H, et al. Ultra-high-resolution computed tomography can demonstrate alveolar collapse in novel coronavirus (COVID-19) pneumonia. Jpn J Radiol. 2020;38:394.

66. Wu J, Zha P. Treatment strategies for reducing damages to lungs in coronavirus and other lung infections. Rochester, NY: Social Science Research Network; 2020. Report No.: ID 3533279. https ://papers.ssrn.com/abstract $=3533279$

67. Liu K-C, Xu P, Lv W-F, Qiu X-H, Yao J-L, Gu J-F, et al. CT manifestations of coronavirus disease-2019: a retrospective analysis of 73 cases by disease severity. Eur J Radiol. 2020;126:108941.

68. Peng Q-Y, Wang X-T, Zhang L-N. Findings of lung ultrasonography of novel corona virus pneumonia during the 2019-2020 epidemic. Intensive Care Med. 2020;46:849.

69. Lai C-C, Liu YH, Wang C-Y, Wang Y-H, Hsueh S-C, Yen M-Y, et al. Asymptomatic carrier state, acute respiratory disease, and pneumonia due to severe acute respiratory syndrome coronavirus 2 (SARS-CoV-2): facts and myths. J Microbiol Immunol Infect. 2020. https://doi.org/10.1016/j.jmii.2020.02.012.

70. Chen N, Zhou M, Dong X, Qu J, Gong F, Han Y, et al. Epidemiological and clinical characteristics of 99 cases of 2019 novel coronavirus pneumonia in Wuhan, China: a descriptive study. Lancet. 2020;395:507-13.

71. SLP Service Delivery Considerations in Health Care During Coronavirus/COVID-19. American Speech-Language-Hearing Association. https://www.asha.org/SLP/healthcare/SLP-Servi
ce-Delivery-Considerations-in-Health-Care-During-Coronaviru s/. Accessed 11 Apr 2020

72. RCSLT guidance. Royal college of speech and language therapists. https://www.rcslt.org/. Accessed 12 Apr 2020

73. Repici A, Maselli R, Colombo M, Gabbiadini R, Spadaccini M, Anderloni A, et al. Coronavirus (COVID-19) outbreak: what the department of endoscopy should know. Gastrointest Endosc. 2020. https://doi.org/10.1016/j.gie.2020.03.019.

74. Zou L, Ruan F, Huang M, Liang L, Huang H, Hong Z, et al. SARS-CoV-2 viral load in upper respiratory specimens of infected patients. N Engl J Med. 2020;382:1177-9.

75. Tran K, Cimon K, Severn M, Pessoa-Silva CL, Conly J. Aerosol generating procedures and risk of transmission of acute respiratory infections to healthcare workers: a systematic review. PLoS ONE. 2012;7:e35797.

76. Vukkadala N, Qian ZJ, Holsinger FC, Patel ZM, Rosenthal E. COVID-19 and the otolaryngologist-preliminary evidencebased review. Laryngoscope. 2020. https://doi.org/10.1002/ lary.28672.

77. COVID-19 Radiology-Specific Clinical Resources. https://www. acr.org/Clinical-Resources/COVID-19-Radiology-Resources. Accessed 11 Apr 2020

78. Guidance for Service Delivery. https://www.speechpathologyaustr alia.org.au/SPAweb/About_us/COVID-19_News_and_Informatio n/COVID-19__Guidance_for_Service_Delivery/SPAweb/About Us/COVID-19/Guidance_for_Service_Delivery.aspx?hkey=fc19a 880-e7a8-4246-8631-a474fc43d4ae. Accessed 11 Apr 2020

79. Perry L, Love CP. Screening for dysphagia and aspiration in acute stroke: a systematic review. Dysphagia. 2001;16:7-18.

80. Streiner DL. Diagnosing tests: using and misusing diagnostic and screening tests. J Pers Assess. 2003;81:209-19.

81. Perren A, Zürcher P, Schefold JC. Clinical approaches to assess post-extubation dysphagia (PED) in the critically Ill. Dysphagia. 2019;34:475-86.

82. Scheel R, Pisegna JM, McNally E, Noordzij JP, Langmore SE. Endoscopic assessment of swallowing after prolonged intubation in the ICU setting. Ann Otol Rhinol Laryngol. 2016;125:43-52.

83. Marvin S, Thibeault S, Ehlenbach WJ. Post-extubation dysphagia: does timing of evaluation matter? Dysphagia. 2019;34:210-9.

84. Schepp SK, Tirschwell DL, Miller RM, Longstreth WT. Swallowing screens after acute stroke. Stroke Am Heart Assoc. 2012;43:869-71.

85. Etges CL, Scheeren B, Gomes E, Barbosa LDR. Screening tools for dysphagia: a systematic review. Codas. 2014;26:343-9.

86. Taveira KVM, Santos RS, de Leão BLC, Stechman Neto J, Pernambuco L, da Silva LK, et al. Diagnostic validity of methods for assessment of swallowing sounds: a systematic review. Braz J Otorhinolaryngol. 2018;84:638-52.

87. See KC, Peng SY, Phua J, Sum CL, Concepcion J. Nurse-performed screening for postextubation dysphagia: a retrospective cohort study in critically ill medical patients. Crit Care. 2016;20:326.

88. Heffner JE. Swallowing complications after endotracheal extubation: moving from "whether" to "how". Chest. 2010;137:509-10.

89. Brodsky MB, González-Fernández M, Mendez-Tellez PA, Shanholtz C, Palmer JB, Needham DM. Factors associated with swallowing assessment after oral endotracheal intubation and mechanical ventilation for acute lung injury. Ann Am Thorac Soc. 2014;11:1545-52.

90. Johnson KL, Speirs L, Mitchell A, Przybyl H, Anderson D, Manos $\mathrm{B}$, et al. Validation of a postextubation dysphagia screening tool for patients after prolonged endotracheal intubation. Am J Crit Care. 2018;27:89-96.

91. de Medeiros GC, Sassi FC, Mangilli LD, Zilberstein B, de Andrade CRF. Clinical dysphagia risk predictors after prolonged orotracheal intubation. Clinics (Sao Paulo). 2014;69:8-14. 
92. Langmore Susan E, Logemann JA. After the clinical bedside swallowing examination. Am J Speech Language Pathol. 1991;1:13-20.

93. Carnaby-Mann G, Lenius $\mathrm{K}$. The bedside examination in dysphagia. Phys Med Rehab Clin N Am. 2008;19:747-68.

94. Carnaby G. Food for thought: perspectives on swallowing and swallowing disorders (dysphagia). Am Speech Lang Hear Assoc. 2012;21:143-9.

95. Admin. Guidance for SLPs during COVID-19—V Apr 72020. Swallowing Rehabilitation Research Lab. 2020. https://steeleswal lowinglab.ca/srrl/guidance-for-slps-during-covid-19-v-apr-72020/. Accessed 12 Apr 2020

Publisher's Note Springer Nature remains neutral with regard to jurisdictional claims in published maps and institutional affiliations. 